\title{
Forming academic/community partnerships to help alleviate the clinical placement crisis
}

\author{
Karen L. Gorton ${ }^{* 1}$, Kathleen B. LaSala ${ }^{2}$ \\ ${ }^{1}$ College of Nursing, University of Colorado, Anschutz Medical Campus, Aurora, CO, United States \\ ${ }^{2}$ College of Nursing, University of South Carolina, Columbia, SC, United States
}

Received: September 5, 2014

DOI: $10.5430 /$ jnep.v5n4p1
Accepted: January 5, $2015 \quad$ Online Published: January 10, 2015

URL: http://dx.doi.org/10.5430/jnep.v5n4p1

\begin{abstract}
Purpose of the article: The finite number of traditional clinical placements in acute care settings is creating pressure for nursing education programs. This article describes the design and successful implementation of a non-traditional, academic clinical partnership established between a faith-based community partner and a baccalaureate nursing degree-granting academic institution.

Design/method: The authors lay out a novel partnership-development concept and operationalize that concept through realworld examples. The goal of the collaborative was to screen clients of the community partner to identify cognitive impairment within this population. Additionally, nursing students were exposed to a collaborative, research project between the academic and community partner.

Findings: The collaborative partnership met mutual goals. Eighty nursing students contacted over 1,400 clients, completed telephone screening of over 1,000 active clients, and performed over 75 in-home assessments for clients of the faith-based community agency. The tools used identified that approximately $30 \%$ of the community partners' clients were living with some form of cognitive impairment.

Conclusions: Both academic and community partners found the partnership effective. Over $80 \%$ of students rated the clinical experience 4 or higher on a 5-point Likert scale. Students reported satisfaction and demonstrated increased sensitivity to independent community-dwelling seniors. The community partner was able to incorporate the tools used in the project into their routine screening process for all clients.
\end{abstract}

Key Words: Alternative clinical placements, Nursing education, Partnerships, Clinical placement

\section{Introduction}

\subsection{Problem background}

Traditionally, nursing education programs have used a combination of didactic, laboratory, and clinical experiences as standard practice. Students are presented with materials in a classroom setting, moved into a laboratory setting for prac- tice, and then eased into the clinical environment to apply both classroom and laboratory learning. More recently, simulation has been added to educational programs. ${ }^{[1-6]} \mathrm{Re}-$ cently, however, the clinical setting - one of the three traditional loci of nursing education-has reached a point of diminishing return by becoming a limiting factor for nursing programs. ${ }^{[7-10]}$

\footnotetext{
${ }^{*}$ Correspondence: Karen L. Gorton; Email: karen.gorton@ucdenver.edu; Address: College of Nursing, University of Colorado Anschutz Medical Campus, Aurora, United States. 
Escalating competition for limited numbers of clinical placements constrains nursing programs and nursing curricula. Many acute care facilities are now (a) very cautious about the number of nursing students allowed to provide direct patient care, (b) no longer allowing students to care directly for patients, or (c) inundated with requests for clinical placements from multiple nursing education programs. In short, the demand for clinical experiences within traditional settings is going up while the number of student experiences allowed in these settings is going down. ${ }^{[1]}$ Clinical placements have been cited as a key factor in turning away qualified applicants to nursing education programs, so nursing education faces a choice: either continue to educate nursing students in the same problematic manner, or seek out innovative, alternative clinical settings to meet educational goals. $^{[12]}$

The search for alternative clinical-educational placements that meet curricular requirements is not a new one. Bartz \& Dean-Baar called for additional atypical clinical models in nursing education to meet the ever-changing needs of patient care, and they cited a successful communitybased clinical partnership. ${ }^{[13]}$ During a five-year span, the community-based agency they described accommodated clinicals for over 100 nursing students, providing the educational program with a learning environment that was outside of acute care yet still met curricular outcomes and educational standards.

Giddens et al. recommended adapting the clinical component while still meeting course and program objectives. ${ }^{[14]}$ Implementing this clinical-component adaptation is not easy, but it can benefit the community and academic partners; most importantly, it can benefit the students. Also supporting adaptation of the clinical component environment are data from the National League for Nursing (NLN). According to the NLN, $89 \%$ of NLN members and $89 \%$ of Board of Nursing representatives agreed that clinical nursing education could occur in any setting. ${ }^{[15]}$ Williams, French, \& Brown, T. have studied the use of DVD simulations for interprofessional education (IPE) to address the shortage of clinical education placement experiences. ${ }^{[16]}$ The findings from this study suggest that DVD simulation activities may present a possible alternative to clinical education within the context of IPE and in turn other clinical experiences. More recently, Hampton described using a constructivist approach to supplement clinical education for pre-licensure nursing students in a Mental Health course. ${ }^{[17]}$ The findings of this small study demonstrated that the structured learning activity was able to meet course learning outcomes. Clearly, the use of alternative and innovative approaches to address the limitations of clinical education has been considered, and used, for over a decade. Furthermore, the Institute of Medicine (IOM) and Benner, Sutphen, Leonard \& Day have called for increasing use of academic/service partnerships and clinical placements out- side the acute care setting, respectively. ${ }^{[18,19]}$

\subsection{Problem statement}

Academic nursing programs' decreased access to traditional patient populations and nursing leaders' calls for nursing education reform should prompt changes in clinical components of curricula. However, development of effective non-traditional partnerships requires time, careful planning, willingness to think creatively, and purposeful collaborative effort.

\section{Method}

\section{Establishing academic/community partnerships}

The authors will share guidelines for establishing alternative clinical placement options while providing a real-world example of a partnership that was developed. Examples of the actual problems and solutions created can assist others as they explore novel partnerships for clinical education experiences. The process of developing non-traditional partnerships can be divided into the following stages: (A) broad foundational steps; (B) foundation-solidifying steps; (C) mobilizing toward launch; (D) pre-launch fine-tuning; (E) development of unique screening tools using well established clinical focused survey type assessments for cognitive impairment. Additionally, outcomes from the project will be presented.

(A)Broad Foundational Steps (BFS): (1) identify a potential community partner (CP); (2) determine if that potential partner has unmet needs; (3) determine if those needs correlate with course objectives of the academic partner (AP).

BFS (1): Identify a potential CP. After determining that its area of need centered on community health, this study's real-world nursing program identified a potential partner that would facilitate a community health emphasis. The $\mathrm{CP}$ was known by the nursing program for services which are provided to community dwelling seniors.

BFS (2): Determine if that potential CP has unmet needs. Informal conversations explored the needs of the $\mathrm{CP}$ as they related to the needs of the nursing program in community health. Through these discussions, both parties felt they would benefit from a partnership.

BFS (3): Determine correlation between CP and AP needs. Formal discussions between the key stakeholders (CP Director, AP Nursing Director) then followed. Subsequently, leaders within the academic institution carefully developed individual and mutual goals, leading to the decision to move forward.

(B) Foundation-solidifying Steps (FsS): (1) identify potential issues and stumbling blocks related to mission, vision, and values of both partners; (2) reaffirm the ability of the partnership to meet the needs of both partners; (3) develop 
and constantly evaluate the infrastructure of the partnership project.

FsS (1): Identify potential issues and stumbling blocks related to mission, vision, and values of both partners. The real-world collaborative partnership was established with a faith-based organization. Potential issues identified by the partners included the following: Would students be excluded from participation if they did not adhere to a specific faith? Would there be any requirements from the $\mathrm{CP}$ that were not in keeping with the philosophical framework of the AP? Throughout early conversations, it was determined that all students, regardless of religious belief, could provide meaningful service for the community partner. It was further decided that the identified needs of the community agency met the specific course objectives of a clinically focused community health course. Early consideration of these questions, which could ultimately have impacted the project, precluded problems arising at a later date.

FsS (2): Reaffirm the ability of the partnership to meet the needs of both partners. In this partnership, the mission of the faith-based CP was to help its clients live as dignified, engaged, independent community-dwelling individuals. This mission was congruent with the objective of the AP's community health course, which focused on student work with community and aggregate populations. The $\mathrm{CP}$ wanted to (1) reach out to all of its past clients (over 1,700) to update records and (2) conduct home visits to assess the service needs of clients. The need of the CP to reach out to older home-dwelling clients fit with the scope of the nursing course, reaffirming that the proposed partnership could satisfy both parties.

FsS (3): Develop the infrastructure of the partnership project. During the development of this unique partnership, in-depth discussions involved the $\mathrm{CP}$ director, key $\mathrm{CP}$ personnel, the academic-program director, and key academicprogram faculty members. Collaborative decisions involved what client data would be assessed, what tools that would be used and how evaluations would completed. Both the $\mathrm{CP}$ and academic-program team members spent extensive time developing the tool to fit the needs of the project. At times, it seemed as if academic-program faculty members were spending more time developing the project tools than on traditional course preparation. However, the realization that tool development would be instrumental to long-term success motivated the partners to continue to work together. Prior to launching the project with students, the phone assessment tool had been revised more than 10 times.

A logic model framework was used to facilitate the infrastructure development. Key people from each partnering institution were engaged in the creation of the logic model to identify the need, context of the need, resources necessary to meet the need, and expected outcomes for the project. The individuals committed to meeting on a weekly basis, and communication parameters were established. During these meetings, they brainstormed about current progress of the project, real and potential barriers that could hinder the project, the discovery of new collaborative strengths within the partnership, and any existing or new threats to the success of the partnership. These meetings allowed both parties to constantly evaluate and modify activities with accurate input from both partners. One concern was the communication by the clinical faculty member to both the AP and CP. It was discovered that what the faculty member was telling the $\mathrm{CP}$ was very different from what was being reported to the AP, and the students verified that what was being relayed to the AP was different from what was occurring. Conversation between the partners ensued, and subsequently, the faculty member was removed from the setting.

(C) Mobilizing toward Launch (MtL): (1) name key communications people; (2) decide which institution will provide the location and supervisory staff for the clinical experience; (3) identify additional resources required to implement the project (e.g., salaries, phone lines, phones, computer access); (4) create system for addressing and authorizing needed changes within the project.

MtL (1): Name key communications people. In this partnership, identification of the key communicators within each partner proved to be important. When questions arose, the key CP would contact the key AP to discuss issues and brainstorm solutions. Not only did this provide clear communication, it also provided each partner with the knowledge that only one person would be contacting the other partner to address issues, keeping communication channels open and well-defined.

MtL (2): Decide which institution will provide the location and supervisory staff for the clinical experience. A difference of opinion arose in the partnership involving student supervision and evaluation. The CP felt that they should supervise and evaluate the students and the AP felt that it was an educational responsibility of the program. After lengthy discussion, it was determined that site supervision would be provided by an AP faculty member who would be placed exclusively at the CP. This clinical faculty member was responsible for evaluation of the student work, similar to all clinical faculty in other clinical settings. This led to an agreement: the ongoing cost would be covered by the AP at the standard rate for clinical faculty. This was a difficult decision for the $\mathrm{CP}$ as they had limited space and were not used to outsiders being present in the building. The project was fortunate to have grant funding for the first year to pay for a supervisor and for the additional costs related to contacting clients, an expense that would need to be visited further once grant funding ended.

MtL (3): Identify additional required resources. Anticipating additional resources remained a constant goal. Early on, the need for computer access and computers was iden- 
tified and addressed, but some items were later identified as the need arose during implementation. The partners did not realize students using the existing two phone lines would make it impossible for the CP to make outgoing calls or get calls from their clients. Additional phones and phone lines were required. Lastly, working space for the students to use during the calls, file folders for completed screening tools, and other general office items needed to be obtained.

MtL (4): Create system for addressing and authorizing needed changes. The partners collaboratively identified the process for changes prior to the project launch. It was determined that both key players from the $\mathrm{CP}$ and $\mathrm{AP}$ would need to work together to determine if change was needed, what change would be implemented and how it would be implemented to minimize the impact on the project and allow for goal achievement for both the CP and AP. As with any project, the amount of time required in the planning stages is intensive and important. Time spent in planning and organization helped yield excellent results when students started to participate.

(D) Pre-launch Fine-tuning (PF): (1) train students and staff; (2) communicate clearly and frequently; (3) adapt to unforeseen issues.

PF (1): Train students and staff. The beginning of student participation marks the formal launch of a collaborative project. It is the time when all planning is tested, systems are taxed in unanticipated ways, and stress can have a negative impact. Students and staff training and orientation to the project were crucial to the success of the project. The development of orientation materials was done by the individual partners and then reviewed and revised by the collaborative group of key stakeholders. Consensus on the orientation materials was obtained and the training of students and staff ensued prior to student placement in the agency.

PF (2): Communicate clearly and frequently. After launching this project, set communication times were arranged for four times a week. There was communication at the end of each student clinical day in the agency with an additional time for a weekly summary meeting.

PF (3): Adapt to unforeseen issues. The quality of the advance planning generally makes or breaks the initial period of student integration. But while planning can address some issues that may arise, not every problem or situation can be anticipated. For example, in this project, it became apparent that clients of the community-based agency were being frightened by the approach to the phone conversation that had been scripted during the planning stage. The on-site faculty member, working with the agency staff member, made the decision to change the script from "Hi, my name is $\mathrm{X}$, and I am a nursing student working with XX agency" to "Hi, my name is X, and I am a volunteer with XX agency." The community partner clientele had an extremely positive response to this change.
(E) Development of screening tools (DST): (1) identify key tools for screenings; (2) modification of tools to work within telephone context; (3) peer evaluation of tools.

DST (1): Identify key tools for screenings. This step required additional input from experts who evaluate individuals within this age population. A board certified physician and licensed psychologist who focused on the population were consulted to determine the best tools to use for this population. These two experts suggested the use of the following tools to screen for cognitive status of the clients: Memory Impairment Screen (telephone version; MIS-t); Visuospatial Learning and Retention Test (VLRT); the CompuStroop Task, and the Observation List for early signs of Dementia (OLD). The partners from both the community and academic partners reviewed the tools with guidance from the content experts. The goal for the tool was to not only gather data related to the client, but to gain some basic insight into the clients' cognitive functioning.

DST (2): Modification of tools to work within the telephone context. The team, partners from the community and academic side with the content experts, collaboratively developed the phone interview tool that was used for initial screening of the clients. This tool, Geriatric Observation Checklist for Telephone (GOCT), was used for initial screening and was composed of the MIS-t, some components of the VLRT, demographic information and general questions the community partner felt were vital information.

DST (3): Peer evaluation of tools: Keeping the goal of gaining basic insight into the cognitive functioning of the client, the board certified physician and licensed psychologist took the GOCT tool to their peers and requested feedback. The tool was deemed to be appropriate for gaining basic insight into cognitive functioning by their peers. The peers also stressed that further evaluation should be completed to assess clients more specifically in the area of cognitive function.

\section{Results/Discussion}

\subsection{Project evaluation: Formative and summative}

A plan for both formative and summative evaluation of the project process and outcomes is essential. Formative evaluation throughout the project provides on-going feedback data that can immediately impact student behaviors as well as client and project outcomes. Summative evaluations of aggregate data from students, faculty, the clinical partner personnel, and the community served should all be included in the assessment. Collaborative data collection and analysis provides everyone involved with a better understanding of the processes and outcomes.

In this partnership, students and agency personnel provided feedback on how the project was progressing via jointly developed formal evaluation tools. Feedback was used to con- 
tinuously improve the project. Feedback from the clients was also used to modify the screening tool and introduction communication used by the students. Summative evaluation was completed by the $\mathrm{CP}$ and $\mathrm{AP}$ at the end of the project. The summative data were used to make changes to improve future iterations of the project, and collaborative data analysis allowed both partners to provide comprehensive, summative reports to their overseeing bodies.

The partners developed the telephone screening tool, the Geriatric Observation Checklist for Telephone (GOCT) which incorporated demographic data, components of the Memory Impairment Screen (MIS-t), and VLRT. Data collected from the tools used over the phone and in the home of the client was also analyzed. The telephone screening tool combined with home visits, where established screening tools for the detection of cognitive impairment were used in this project. The telephone version of the MIS- $t$ was incorporated into the telephone screening questions to screen for dementia. When the MIS-t demonstrated concerns related to memory, a home visit to follow up was initiated. In the home, the Visuospatial Learning and Retention Test (VLRT), the CompuStroop and the Observation List for early signs of Dementia (OLD) were adopted for the in home screening. While the OLD was not validated for in home screenings, it was used in this setting for screening purposes.

The final version of the phone interview included the GOCT, a checklist of 43 abnormal behavioral characteristics in the areas of communication, orientation, executive attention, and neuropsychiatric symptoms that are often associated with neurocognitive decline that could be observed without face-to-face contact. Because actual medical symptomatology was reported by so few participants, efficacy of the GOCT was examined by relating it to the functional independence measure of ability to independently prepare meals (which served as a proxy measure of neurocognitive health). There was a trend for scores on the GOCT to be related to functional dependence, or inability to perform this task, $p=$ $.06, F(1,25)=3.88$.

Based upon the limited screening done, it was estimated that $30 \%$ of the clients of the community partner were living with some form of cognitive impairment. Additionally, approximately one third of the community partner clients demonstrated some form of subclinical cognitive impairment. It was not known if these results were related to true cognitive impairment or related to the home visit experience for the clients. When cognitive impairment was discovered, clients were encouraged to contact their primary care provider for further evaluation. This recommendation was presented to the client both verbally and in written format. Both the community and academic partner felt strongly about referral for further evaluation that came from the client. The community partner did not want to cross any lines related to confidentiality with their clients.

\subsection{Final project-evaluation reports}

Final project-evaluation reports use the collaboratively developed assessment tools and summative/formative data analyses to capture accurately the process and outcomes of the collaborative project. The analysis can include a review of what worked well and what areas need improvement or deletion. Potential solutions can be identified and implemented if the partnership is ongoing. It is critical to include the target population (i.e., the clients or communities served) in the evaluation. Focus groups and surveys are effective tools. Additionally, the logic model can assist in understanding the impact of the project upon the clients and students.

Over the course of one academic year, the eighty nursing students involved in this project were able to make contact with over 1,400 clients of the community agency. For over 1,000 of these clients, medical record and contact information was updated, a mental-status assessment was initiated, and referrals for home visits were made. Additionally, the nursing students were able to participate in over 75 home visits of clients where further mental-status evaluation was undertaken. This partnership was awarded grant funding, and the evaluation by the funding organization found the partnership to be "extremely collaborative, open, and meeting the goals of the initial proposal".

Additionally, solid data related to the cognitive impairment of the community partner's clients was gathered. The tools used and developed in this partnership were incorporated into the standard intake screening process for all clients of the community partner. With approximately $30 \%$ of the clients demonstrating some level of cognitive impairment, it demonstrates the heightened need for all nursing professionals to understand how to screen individuals on a variety of levels.

The partners knew that the outcome goal was a high-quality, meaningful project that would benefit both partners. Both partners were pleased with the outcome, an outcome that evolved from some initial brainstorming related to needs and clinical placements. This was an atypical clinical setting that met (a) course objectives for the nursing program, (b) identified needs of the community-based agency, (c) and served the needs of the community. The nursing program learned that settings outside the traditional acute-care setting can both be very meaningful for the students and meet course objectives.

\section{Conclusions}

Finding clinical placements in new settings can be beneficial to academic and community partners while providing students with opportunities to learn and serve. There are some essential steps to establishing new academic/community partnerships, including the following: 
- Identify potential community partner

- Determine if potential partner has unmet needs that nursing students could meet to some level

- Determine if potential partner's need would align with course objectives

- Be pragmatic about goodness of fit, allowing for possibility that the project will not work

- Consider seeking external funding to support develop and pilot project

- Maintain open communication on frequent basis with key individuals

- State clearly expectations for students, for nurse supervising students, for academic partner, and for community partner

- Determine process for changes that should be implemented

- Determine process for changes that must be implemented

- Determine process for direct supervision of on-site faculty members

- Identify key resource people within each partner organization

- Plan training for both students and agency personnel

- Be willing to change as both partners learn about

\section{References}

[1] Gantt, L. T. Using the Clark simulation evaluation rubric with associate degree and baccalaureate nursing students. Nursing Education Perspectives. 2010; 31: 101-105. PMid:20455367

[2] Rourke, L., Schmidt, M., Garga, N. Theory-based research of high fidelity simulation used in nursing education: A review of the literature. International Journal of Nursing Education Scholarship. 2010; 7(1): 1-14. PMid:20361859 http://dx.doi.org/10.2202/154 8-923X. 1965

[3] Cant, R. P., Cooper, S. J. Simulation-based learning in nurse education: Systematic review. Journal of Advanced Nursing. 2009; 66(1): 3-15. PMid:20423432 http://dx.doi.org/10.1111/j $.1365-2648.2009 .05240 . x$

[4] Lasater, K. Clinical judgment development: Using simulation to create an assessment rubric. Journal of Nursing Education. 2007; 46: 496-503. PMid: 18019107

[5] Schumacher, L. The impact of using high-fidelity computer simulation on critical thinking abilities and learning outcomes in undergraduate nursing students. Dissertation Abstracts International. 2004; 65(10b).

[6] Ravert, P. An integrative review of computer-based simulation in the education process. CIN: Computers, Informatics, Nursing. 2002; 20(5): 203-208.

[7] American Association of Colleges of Nursing (AACN). Enrollment growth in US nursing colleges and universities hits an 8year low according to new data released by AACN. 2008. Available from: http://www.aacn.nche.edu/news/articles/20 08/enrlgrowth

[8] AACN. Amid calls for more highly educated nurses, new AACN data show impressive growth in doctoral nursing programs. 2010. Available from: http://www.aacn.nche.edu/media/newsre leases/2010/enrollchanges.html

[9] AACN. AACN releases preliminary data from 2012 annual survey. 2012. Available from: http://www.aacn.nche.edu/news/art icles/2012/enrolldata project and as unexpected contingencies arise

- Keep accurate data/records to be used to implement new intake processes.

- Consult with appropriately trained individuals for the development of screening tools

- Develop a referral system when issues are discovered from the assessments

As academic/community partnerships are established, there must be careful attention to detail. In the project presented here, some issues arose; however, the high level of commitment and planning by both the academic and community partners allowed both parties to deal successfully with the issues and ultimately have a project that met everyone's goals. Clients of the community based agency who were living with some level of cognitive impairment were identified and contacted on a more frequent basis. Outcomes from this type of partnership have the potential to not only meet needs of both partners, but have the real potential to impact community health via the creation of a health improvement model.

\section{Conflicts of Interest Disclosure}

The authors declare that there is no conflict of interest statement. Both authors have NO conflict of interest.

[10] AACN. AACN finds slow enrollment growth at schools of nursing. 2014. Available from: http://www.aacn.nche.edu/news/art icles/2014/slow-enrollment

[11] Colorado Council of Nursing Educators (CCNE). 2013; Spring meeting.

[12] AACN. Nursing shortage fact sheet. 2014. Available from: http://www.aacn.nche.edu/media-relations/fact-she ets/nursing-shortage

[13] Bartz, C., Dean-Baar, S. Reshaping clinical nursing education: An academic-service partnership. Journal of Professional Nursing. 2003; 19(4): 216-222. http://dx.doi.org/10.1016/S8755-7 223(03) 00090-5

[14] Giddens, J., Brady, D., Brown, P., Wright, M., Smith, D., Harris, J. A new curriculum for a new era of nursing education. Nursing Education Perspectives. 2008; 29(4): 200-204. PMid:18770947

[15] National League for Nursing. Summary of the Survey on Clinical Education in Nursing. Nursing Education Perspectives. 2008; 29(4): 238-245.

[16] Williams, B., French, J., \& Brown, T. Can interprofessional education DVD simulations provide an alternative method for clinical placements in nursing? Nurse Education Today. 2009; 29(2009): 666-670. PMid:19303674 http://dx.doi.org/10.1016/j.ned t.2009.02.008

[17] Hampton, M. Constructivism applied to psychiatric-mental health nursing: An alternative to supplement traditional clinical education. International Journal of Mental Health Nursing. 2012; 21: 60-68. PMid:21676137 http://dx.doi.org/10.1111/j.1447-0349. 2011.00755.x

[18] Institute of Medicine. The future of Nursing: Leading change, advancing health. Washington, D.C. The National Academies Press. 2011.

[19] Benner, P., Sutphen, M., Leonard, V., Day, L. Educating nurses: A call for radical transformation. San Francisco, CA: Jossey-Bass. 2010 . 